\title{
The Formation of Wider and Deeper Clouds as a Result of Cold-Pool Dynamics
}

\author{
LINDA SCHLEMMER AND CATHY HOHENEGGER
}

Max Planck Institute for Meteorology, Hamburg, Germany

(Manuscript received 12 June 2013, in final form 3 February 2014)

\begin{abstract}
This study investigates how precipitation-driven cold pools aid the formation of wider clouds that are essential for a transition from shallow to deep convection. In connection with a temperature depression and a depletion of moisture inside developing cold pools, an accumulation of moisture in moist patches around the cold pools is observed. Convective clouds are formed on top of these moist patches. Larger moist patches form with time supporting more and larger clouds. Moreover, enhanced vertical lifting along the leading edges of the gravity current triggered by the cold pool is found. The interplay of moisture aggregation and lifting eventually promotes the formation of wider clouds that are less affected by entrainment and become deeper. These mechanisms are corroborated in a series of cloud-resolving model simulations representing different atmospheric environments. A positive feedback is observed in that, in an atmosphere in which cloud and rain formation is facilitated, stronger downdrafts will form. These stronger downdrafts lead to a stronger modification of the moisture field, which in turn favors further cloud development. This effect is not only observed in the transition phase but also active in prolonging the peak time of precipitation in the later stages of the diurnal cycle. These findings are used to propose a simple way for incorporating the effect of cold pools on cloud sizes and thereby entrainment rate into parameterization schemes for convection. Comparison of this parameterization to the cloud-resolving modeling output gives promising results.
\end{abstract}

\section{Introduction}

The diurnal cycle of moist convection over continents and, in particular, the transition from shallow to deep convection is a fundamental process of the climate system. However, a thorough understanding of the mechanisms that promote the formation of deeper clouds and that determine the timing of maximum cloud depth and peak precipitation rates is still lacking. Thus, parameterization schemes struggle to accurately represent the diurnal cycle of convection in global climate models (e.g., Betts and Jakob 2002; Bechtold et al. 2004).

Several mechanisms have been proposed to explain the successive deepening of clouds. One frequently discussed mechanism is an increase of the cloud diameter (Kuang and Bretherton 2006; Khairoutdinov and Randall 2006). Thereby the positively buoyant cloud cores are shielded from dilution through entrainment

Corresponding author address: Linda Schlemmer, Max Planck Institute for Meteorology, Bundesstr. 53, Hamburg 20146, Germany.

E-mail: linda.schlemmer@mpimet.mpg.de and clouds can grow deeper [e.g., de Rooy et al. (2013), and references therein]. Cold pools resulting from the evaporation of precipitation and the presence of penetrative downdrafts have often been mentioned to explain the increase of the degree of organization of convectionmeaning the aggregation of clouds into larger clusters. In their modeling study of an idealized transition to deep convection over Amazonia, Khairoutdinov and Randall (2006) noted that, if the formation of cold pools is suppressed, the clouds remain small in size and the transition is inhibited. Böing et al. (2012) also showed that the presence of cold pools promotes deeper, wider, and more buoyant clouds with higher precipitation rates. This relationship has however not been explained in physical terms. It is also not included in current global climate models.

Observational evidence of cold-pool-generated convective cells is available for shallow maritime convection (Warner et al. 1979; Zuidema et al. 2012), maritime deep convection (Barnes and Garstang 1982; Addis et al. 1984; Young et al. 1995), and continental deep convection (e.g., Lima and Wilson 2008; Lothon et al. 2011; Dione et al. 2013). There is moreover a large amount of 
literature on the role of cold pools in the organization of multicell convection such as squall lines (e.g., Wakimoto 1982) or mesoscale convective systems (e.g., Fritsch and Forbes 2001; Engerer et al. 2008). Typically cold pools are observed in conjunction with penetrative downdrafts that transport cold and dry air from the middle troposphere into the boundary layer. Following Barnes and Garstang (1982), these dry downdrafts or downbursts occur if the precipitation rate exceeds $2 \mathrm{~mm} \mathrm{~h}^{-1}$. For the strength of the downdrafts prior to the evolution of the cold pool, both the size distribution of the raindrops and the lapse rate of the environment have been stressed as governing factors (e.g., Kamburova and Ludlam 1966; Srivastava 1985). Moreover, the humidity of the environment, through its influence on the evaporation rate of rain as well as melting of hail and graupel, crucially impacts the induced cooling (Srivastava 1987).

This pinpoints to an ambiguous relationship between cold pools and precipitation. For a very dry atmosphere the highest evaporation rates and strongest downdrafts are to be expected, which in principle favors strong cold pools. Cloud and rain formation will however be very limited in such an atmosphere. In contrast, in an atmosphere close to saturation, where the formation of clouds and rain is facilitated, reevaporation of precipitation will be hampered and cold pools may turn out as rather weak [see, e.g., Bony and Emanuel (2005), their Eq. (19)].

Different mechanisms have been described to explain how evaporatively driven cold pools support the triggering and organization of deep convective cells. Besides the aforementioned change in cloud size, the cold air at the surface acts as a density current lifting boundary layer air along its leading edge to its level of free convection (LFC). This process has mainly been discussed in the context of multicell organized convection (e.g., Byers and Braham 1949; Lin et al. 1998). Lima and Wilson (2008) documented the triggering of secondary cells by spreading cold pools in the afternoon during the Tropical Rainfall Measuring Mission Large-Scale BiosphereAtmosphere (TRMM-LBA) project. Moreover, Rio et al. (2009) could effectively prolong the peak time of precipitation by including this dynamical effect as a gust front parameterization into their convection scheme. An efficient delay of the peak time of precipitation could however also be achieved (Bechtold et al. 2014) by introducing a coupling coefficient between the boundary layer and the free troposphere that keeps parts of the boundary-layer-generated convective available potential energy (CAPE) from being consumed by convection in the morning hours.

The occurrence of a band with high equivalent potential temperature and water vapor along the edge of already recovered cold pools has further been highlighted by Tompkins (2001b) as a key factor for the triggering of new convective cells. Following this study, moisture that stems from the evaporation of rain is pushed outward by the outflowing density current. Buoyancy will be positive in this moist area facilitating cloud development. An aggregation of moisture around the edges of the cold pools and the subsequent preferred cloud development on these moist spots has been witnessed in simulations of organized shallow convection (Seifert and Heus 2013). In their composite analysis of observed cold pools, Young et al. (1995) noted, moreover, a depression in the surface air temperature of 2-3 K that was followed by a decrease of the mixing ratio of $0.3-1 \mathrm{~g} \mathrm{~kg}^{-1}$. The ability of density currents to transport moisture from the wet monsoon areas into the very dry Sahara, where subsequent cloud development occurs, has in addition been documented in Flamant et al. (2009). Moisture variations in general have been mentioned as an important aspect in the formation (Zhang and Klein 2010; Chaboureau et al. 2004) and organization (Tompkins 2001a) of deep convection. The modulation of the moisture in the subcloud layer through cold-pool dynamics has however received less attention than the dynamical effect of cold pools and is also not included in convective parameterizations.

The overall aim of the paper is to better understand the role of cold pools for the diurnal cycle of deep convection with a focus on continental convection. To strengthen our findings and be able to better isolate the effects of cold pools, the overall impact of cold pools on the cloud-size distribution under different atmospheric conditions is investigated. A first emphasis is on the often observed relationship between cold pools and larger clouds. Both a physical explanation to this behavior and a simple parameterization to represent it in convection schemes will be provided. A second emphasis is on the possible similarities and discrepancies that exist in the way cold pools act under different environments.

In section 2 the setup of the model and the experiments are described. The results from the simulations are presented in section 3 , followed in section 4 by a suggestion on how to include such cold-pool effects into a parameterization scheme for deep convection. A summary is provided in section 5 .

\section{Setup}

\section{a. Model description and experimental setup}

Simulations were performed using the University of California, Los Angeles (UCLA) large-eddy simulation (LES) model [see Stevens et al. (2005)]. The UCLA-LES has mostly been used to simulate shallow convection 

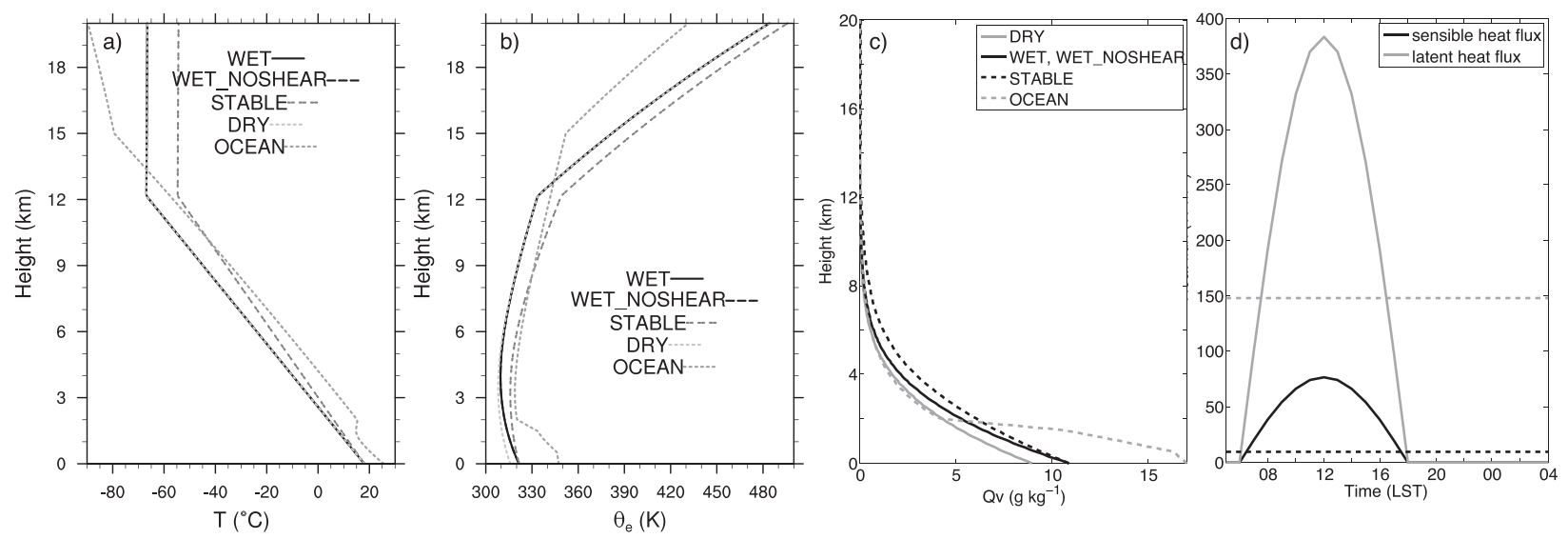

FIG. 1. Atmospheric profiles of (a) temperature $\left({ }^{\circ} \mathrm{C}\right)$, (b) equivalent potential temperature (K), (c) specific humidity $\left(\mathrm{g} \mathrm{kg}^{-1}\right)$, and (d) prescribed turbulent surface fluxes $\left(\mathrm{W} \mathrm{m}^{-2}\right)$ of heat (black) and moisture (gray) for the continental simulations (solid lines) and OCEAN (dashed lines) as function of local standard time.

(e.g., Siebesma et al. 2003) but has recently been advanced to deep convection modeling [see Hohenegger and Stevens (2013)]. The UCLA-LES model solves the three-dimensional Ogura-Phillips anelastic equations, where one assumes an isentropic background state. It uses a third-order Runge-Kutta scheme for the time integration, a fourth-order centered scheme for the advection of momentum, and a flux-limited fourth-order upwind scheme for the advection of scalars. A Smagorinsky-type scheme is employed to represent subgrid-scale mixing. A full two-moment ice microphysics scheme including ice, snow, graupel, and hail as cold species as developed by Seifert and Beheng (2006) is used. The inclusion of the ice phase is important for the formation of downdrafts (and thus cold pools) owing to the additional latent heat required for melting. An adequate representation of the characteristic fall velocities of the hydrometeors is achieved by using the two-moment scheme with a separate treatment for graupel and hail. Moreover, a radiation package (Pincus and Stevens 2009) that has been extended to include the interaction of ice clouds, following $\mathrm{Fu}$ and Liou (1993), is employed. Radiative fluxes are calculated using the "correlated $k$ " method whereas radiative transfer is approximated utilizing a $\delta$-four-stream method.

Surface fluxes of heat and moisture are prescribed at the lower boundary to remain comparable to other LES studies on similar topics (Kuang and Bretherton 2006; Khairoutdinov and Randall 2006; Böing et al. 2012). This implies that the interactions between cold pools and surface fluxes cannot be represented. This effect has so far mostly been shown to be important for oceanic convection (e.g., Johnson and Nicholls 1983; Young et al. 1995; Ross et al. 2004), whereas our study focuses on continental convection. Nevertheless, to investigate the effect of prescribed surface fluxes on the results, one simulation has been repeated using an interactive land surface model. The characteristics of the cold pools and their link to the cloud size remained similar (not shown).

The computational domain comprises $1024 \times 1024 \times$ 100 grid points, corresponding to $256 \times 256 \mathrm{~km}^{2}$ in the horizontal and is centered at $48^{\circ}$ latitude. The horizontal grid spacing is $250 \mathrm{~m}$. In the vertical a stretched grid with a spacing of $70 \mathrm{~m}$ close to the surface and $216 \mathrm{~m}$ at a height of $7 \mathrm{~km}$ is used. There are 14 layers within the lowest $1000 \mathrm{~m}$. The top of the model is at $21020 \mathrm{~m}$ with a sponge layer starting at $18119 \mathrm{~m}$. Doubly periodic lateral boundary conditions are used. In the initialization phase random noise with an amplitude of $0.2 \mathrm{~K}$ $\left(0.05 \mathrm{~g} \mathrm{~kg}^{-1}\right)$ is applied to the temperature (moisture) field in the lowest $200 \mathrm{~m}$.

The grid spacing of $250 \mathrm{~m}$ enables an accurate representation of deep convection, whereas boundary layer processes and shallow convection are only partially resolved. Strictly speaking the LES range is not entered and simulations have not properly converged yet. The simulations are thus termed "cloud resolving" instead of "LES," but one should keep in mind that the employed grid spacing is one order of magnitude finer than what has traditionally been referred to as cloud-resolving simulations.

\section{b. Initial conditions}

The core experiments are based on idealized settings depicting typical midlatitude summertime conditions over land. They closely follow the experiments introduced in Schlemmer et al. (2012). Simulations are started at 0500 LST 12 July. To investigate the behavior of cold pools in different atmospheric environments, four different experiments are conducted: STABLE, DRY, WET, and WET_NOSHEAR. The initial profiles for the experiments are shown in Fig. 1. STABLE, WET, 
and WET_NOSHEAR use the same relative humiditynamely $85 \%$ and $55 \%$ in the lower $(0-2 \mathrm{~km})$ and upper $(8-10 \mathrm{~km})$ troposphere, respectively, with a tanh-shaped profile in between. In DRY, relative humidity is decreased by $15 \%$ throughout the whole column. Temperature decreases linearly with height up to $12.2 \mathrm{~km}$ and remains constant thereafter. The lapse rate is $-0.7 \mathrm{~K}(100 \mathrm{~m})^{-1}$ in DRY, WET, and WET_NOSHEAR and $-0.6 \mathrm{~K}$ $(100 \mathrm{~m})^{-1}$ in STABLE. Combination of the temperature and relative humidity profiles gives the profiles of equivalent potential temperature $\theta_{e}$ as displayed in Fig. $1 \mathrm{~b}$. Zonal wind increases from a value of $2 \mathrm{~m} \mathrm{~s}^{-1}$ at the surface to $17 \mathrm{~m} \mathrm{~s}^{-1}$ at the jet-stream level and becomes westerly in the stratosphere (not shown). Meridional wind is set to zero. The WET_NOSHEAR simulation is identical to WET but the wind shear has been removed and zonal wind is set to $6 \mathrm{~m} \mathrm{~s}^{-1}$ everywhere. Hence, in comparison to WET, WET_NOSHEAR, DRY, and STABLE isolate wind shear, relative humidity, and stability effects.

Turbulent surface fluxes are prescribed at the lower boundary. They are constructed utilizing a sine function for the available energy with a value of $460 \mathrm{~W} \mathrm{~m}^{-2}$ at the apex that is split into latent and sensible heat flux using a Bowen ratio of 0.2. Maximum heat fluxes are thus 383 and $77 \mathrm{~W} \mathrm{~m}^{-2}$, respectively (see Fig. 1d). These values are consistent with those retrieved with a full land surface model in the wet-soil case of Schlemmer et al. (2012). Two supplementary simulations were performed to investigate the effects of the chosen Bowen ratio on the results. One using a Bowen ratio of 1.0 and the other one coupled to an interactive land surface model depicting a Bowen ratio of $\sim 0.5$. These simulations did not show any marked differences in the impact of cold pools onto the further development of convection. They are thus not discussed here.

The analysis of cold-pool effects in section 3 is restricted to WET, WET_NOSHEAR, STABLE, and DRY. To test the generality of the results, one additional experiment, called OCEAN, is performed. It is inspired by the case described in Waite and Khouider (2010) mimicking the deepening of convection over tropical oceans in a relatively dry atmosphere. To be consistent with STABLE, DRY, WET, and WET NOSHEAR and in opposition to Waite and Khouider (2010), prescribed surface fluxes of heat and moisture as well as an interactive radiation scheme are employed. The sensible heat flux is set to $9.12 \mathrm{~W} \mathrm{~m}^{-2}$ and the latent heat flux to $148 \mathrm{~W} \mathrm{~m}^{-2}$. Note also that the employed domain is considerably larger than in the original study of Waite and Khouider (2010) to allow for sufficient space for compensating subsidence and spreading of cold pools. The domain is centered at $32^{\circ}$ and the simulation integrated for $29 \mathrm{~h}$. The atmospheric conditions are untypical for oceanic deep convection owing to the very dry troposphere and hence strong difference in $\theta_{e}$ between the surface and its minimum value in the vertical. It is nevertheless interesting to include this case as it exhibits a cold-pool evolution that is very different from WET, WET_NOSHEAR, STABLE, or DRY.

\section{c. Identification of cold pools, moist patches, and clouds}

One aim of this study is to extract the characteristics of developing cold pools in different environmental conditions and to relate them to the cloud-size distribution. This requires an identification of cold pools, cloud sizes, and related characteristics. A cold pool is identified as soon as $\Delta \theta_{e}$ drops below a chosen threshold of $-2.0 \mathrm{~K}$. Then, $\Delta \theta_{e}$ is defined as the difference between the vertically averaged equivalent potential temperature at a point with respect to its domain mean value:

$$
\Delta \theta_{e}(x, y)=\frac{1}{z_{2}-z_{1}}\left[\int_{z_{1}}^{z_{2}} \theta_{e}(x, y, z) d z-\overline{\int_{z_{1}}^{z_{2}} \theta_{e}(x, y, z) d z}\right],
$$

where $z_{1}=35 \mathrm{~m}$ (corresponding to the lowest atmospheric layer); $z_{2}=525 \mathrm{~m}$ (corresponding to the ninth atmospheric layer); and $x, y$, and $z$ are the zonal, meridional, and vertical direction, respectively. Note that $\int_{z_{1}}^{z_{2}} \theta_{e}(x, y, z) d z$ is also influenced by the cold pools.

By definition, a cold pool is thus not only a region of cold but also dry air. The main motivation to use $\theta_{e}$ is its conservation property under condensation and evaporation. By vertical averaging we ensure that only cold pools with a certain vertical extent are considered. Connected regions of identified points are then clustered based on four connectivity (i.e., two pixels belong to the same cluster if they share a common edge). The employed definition of cold pools entails several subjective choices: the threshold of $-2 \mathrm{~K}$, the integral bands $z_{1}$ and $z_{2}$, or the use of a horizontal average over the entire domain. These choices are motivated by visual inspection of the $\theta_{e}$ field. Tests have been performed with other thresholds or integral bands and gave similar results. Defining cold pools in terms of $\theta_{e}$ favors dry penetrative downdrafts and excludes those where the boundary layer temperature and humidity changes are dominated by evaporation of rainwater within the subcloud layer. Regions of decreased $\theta_{e}$ coincide with regions of decreased potential temperature $\theta$ (not shown). Thus, these definitions are not independent. For the observational studies of Young et al. (1995) and Zuidema et al. (2012) it was nevertheless stated that 

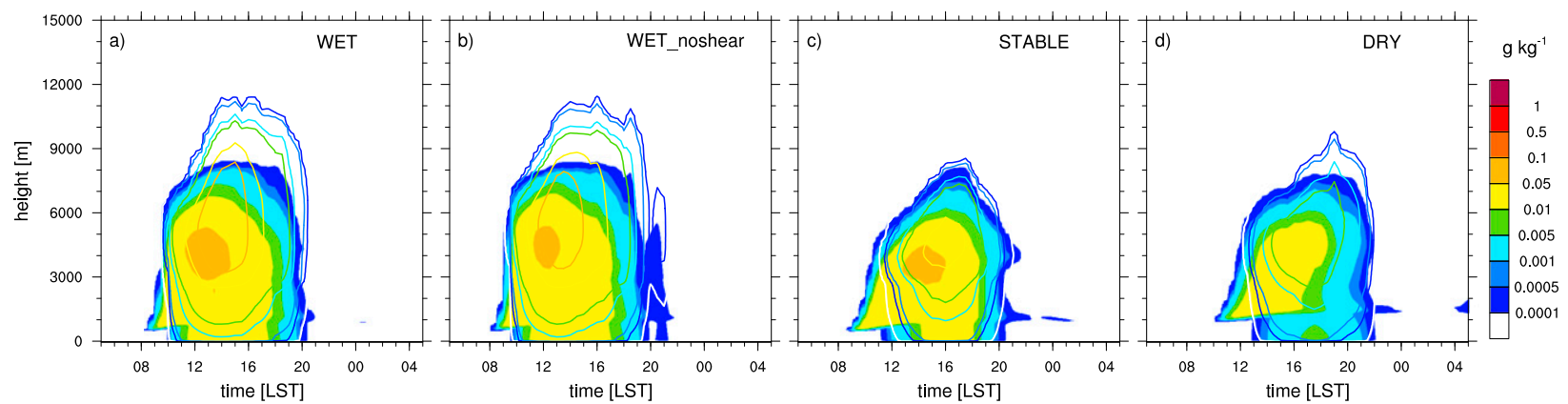

FIG. 2. Time-height plots of domain-mean values of the sum of cloud liquid and rain mixing ratio (shaded $\operatorname{area} \mathrm{g} \mathrm{kg}^{-1}$ ) and the sum of cloud ice, snow, graupel, and hail mixing ratios (contour lines; $\mathrm{g} \mathrm{kg}^{-1}$ ).

these evaporation-dominated cases are characterized by minor precipitation events. The studies of Young et al. (1995) and Zuidema et al. (2012) considered both rain rate and a shift of the wind direction to identify cold pools, whereas Addis et al. (1984) concentrated on a drop in the virtual temperature. In the modeling studies of Khairoutdinov and Randall (2006) or Böing et al. (2012) a definition of cold pools was omitted. There is thus no clear well-established way to define cold pools.

Similarly, moist patches, that is, connected regions of enhanced moisture, are identified if $\Delta q$, the difference of the vertically averaged $(35-525 \mathrm{~m})$ water vapor mixing ratio to its domain-mean value, exceeds $0.5 \mathrm{~g} \mathrm{~kg}^{-1}$. Connected regions are then clustered. Even if in theory cold pools and moist patches could overlap they do not seem to do so as cold pools tend to represent dry areas. Finally, grid points with a liquid water content larger than $1.0 \mathrm{mg} \mathrm{kg}^{-1}$ at a height of $1300 \mathrm{~m}$ are referred to as cloudy. The level $1300 \mathrm{~m}$ was chosen as it roughly corresponds to the cloud base in all simulations conducted (except in OCEAN, where a height of $945 \mathrm{~m}$ is chosen). Cloud sizes are determined by summing up all points within a connected region, irrespective of the geometry of the cloud cluster. As will be shown convective clouds tend to aggregate into larger clusters. We refer to this process as "organization of convection."

\section{Simulation results}

\section{a. Overview}

Figures 2 and 3 depict the diurnal cycle of simulated hydrometeors, and surface rain rate for the set of simulations and key quantities are summarized in Table 1. In all simulations, deep, precipitating convection develops. The overall picture shows a qualitatively similar behavior to the simulations of Schlemmer et al. (2012). In WET, first shallow clouds develop in the morning from 0830 LST onward. Convection then gradually deepens and ice processes eventually become important. After a congestus phase between 1000 and 1300 LST maximum cloud depth is reached around 1400 LST. Cloud tops reach up to $12 \mathrm{~km}$. The resulting diurnal cycle of surface precipitation is shown in Fig. 3. The onset of precipitation at the surface is at 1000 LST and precipitation peaks around 1330-1600 LST. Ongoing deep convection consumes the available instability and stabilizes the atmosphere. Thus, convection ceases during the late evening. The domain chosen is presumably too small to allow parts of the area to remain quiescent during daytime and convection to be triggered there during nighttime first.

In WET_NOSHEAR, convection and surface precipitation start slightly earlier than in WET. The time of maximum precipitation is shortened and precipitation starts to decay at 1300 LST. Thus, it is first harder for clouds to deepen when wind shear distorts them but, once they have deepened sufficiently, wind shear helps sustaining the convection and precipitation. In STABLE the deepening of clouds progresses at a slower rate and the peak cloud-top height remains below $9 \mathrm{~km}$. Surface precipitation is in addition considerably delayed and of weaker amplitude. In DRY the penetration of clouds beyond $8 \mathrm{~km}$ occurs at $1600 \mathrm{LST}$ as compared to 1100 LST in WET. Yet, at this time surface fluxes have already decreased notably and a final transition into mature deep convection is only occurring at a few spots in the domain. This expresses itself in very low surface precipitation amounts.

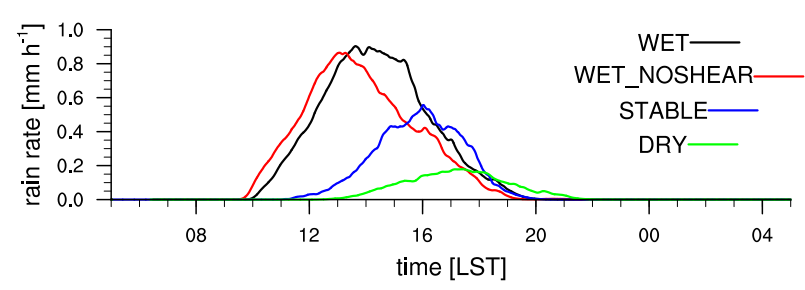

FIG. 3. Domain-mean surface precipitation rate $\left(\mathrm{mm} \mathrm{h}^{-1}\right)$ for the cases. 
TABLE 1. Peak rain rates, maximum $\Delta \theta_{e}$, size of the largest cold pool $A_{\mathrm{cp}}$, maximum $\Delta q$, size of the largest moist patch $A_{\mathrm{mp}}$, and maximum cloud size $A_{c}$ for the simulations conducted.

\begin{tabular}{lcccccc}
\hline \hline \multicolumn{1}{c}{ Simulation } & $\begin{array}{c}\text { peak rain rate } \\
\left(\mathrm{mm} \mathrm{h}^{-1}\right)\end{array}$ & $\max \Delta \theta_{e}(\mathrm{~K})$ & $\max A_{\mathrm{cp}}\left(\mathrm{km}^{2}\right)$ & $\max \Delta q\left(\mathrm{~g} \mathrm{~kg}^{-1}\right)$ & $\max A_{\mathrm{mp}}\left(\mathrm{km}^{2}\right)$ & $\max _{c}\left(\mathrm{~km}^{2}\right)$ \\
\hline WET & 0.90 & -11.6 & 3000 & 2.46 & 16500 & 232 \\
WET_NOSHEAR & 0.86 & -11.3 & 781 & 2.17 & 2790 & 63.6 \\
STABLE & 0.56 & -9.35 & 1040 & 1.81 & 635 & 122 \\
DRY & 0.18 & -9.31 & 886 & 1.68 & 187 & 76.4 \\
$\theta_{e, \text { const }}$ & 0.61 & -6.20 & -23.2 & 4070 & 2.17 & 23900 \\
OCEAN & 0.21 & & & & 50.6 \\
\hline
\end{tabular}

Figure 4 gives a visualization of the cold pools and their possible effects on the convective development. Cold pools produce patches of dry and cold air at the surface that stem from the free-atmospheric air that is pushed into the boundary layer by penetrative downdrafts. In the moisture field this is visible as dry areas (see, e.g., in locations A and B of Fig. 4a) that are surrounded by walls or towers of moisture, upon which clouds tend to sit. These regions of enhanced moisture correspond to the "moist patches" as formally defined in section 2c. An illustration of such a moist patch is visible in the middle between label A and B in Fig. 4a. These moist rims have also been mentioned in Tompkins (2001b) as areas of increased buoyancy that favor the triggering of clouds. It is not clear from the current study if the additional moisture in these wet regions stems from earlier evaporation of precipitation as stated in Tompkins (2001b) or if the moisture present before the impact of the downdraft is pushed outward by the density current and transferred onto moist patches. A rough estimate comparing the tendencies on the water vapor from the microphysical scheme to the moisture anomaly of the moist patch suggests that only $10 \%$ of the moisture stems from direct evaporation. A $2 \mathrm{D}$ view of the $\Delta \theta_{e}$ field and the identified cold pools, moist patches, and clouds (see section $2 \mathrm{c}$ for their definition) is given in
Fig. 4b. This confirms that cold pools are surrounded by moist patches on which clouds are located and that our detection algorithm method works. The formation of these moist patches and their implications for further cloud development is investigated in section $3 \mathrm{c}$.

The downdraft air spreads along the surface as a gravity current associated with a gust front. Neighboring gust fronts end up colliding, as visible in Fig. 4c by the distribution of the near-surface vertical velocity. Clouds are located on these convergence zones and are most pronounced on regions where multiple cold pools collide. Between the quiet cold-pool areas there are regions with lifting of a comparable magnitude, but these have substantially finer structures and stem from regular Rayleigh-Bénard convection. The role of these convergence zones is discussed in section $3 \mathrm{~d}$. Comparison of Figs. $4 \mathrm{~b}$ and $4 \mathrm{c}$ further indicates that the regions of enhanced convergence and increased moisture overlap, which makes a distinction of their effect difficult.

Although Fig. 4 suggests a link between precipitation, cold pools, and moist patches, other atmospheric processes, especially convective boundary layer turbulence, could generate such moisture anomalies. Figures 5a and $5 \mathrm{~b}$ illustrate the size of the largest cold pools and moist patches found in the domain as a function of surface sensible heat fluxes for the different cases. The surface
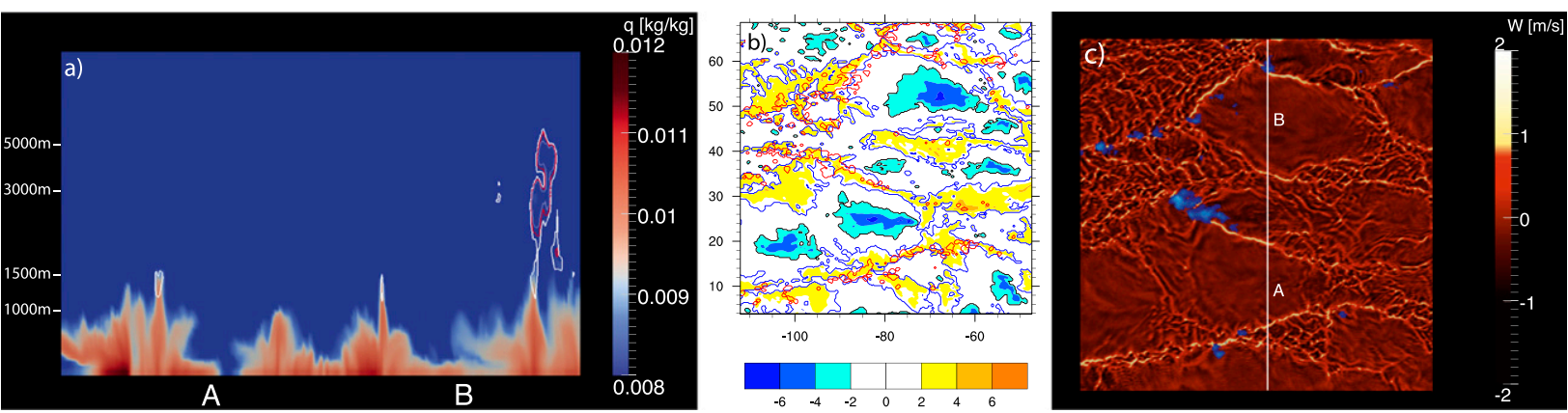

FIG. 4. (a) Total water mixing ratio ( $\mathrm{kg} \mathrm{kg}^{-1}$; shading) and $0.5,1.0$, and $1.5 \mathrm{~g} \mathrm{~kg}^{-1}$ isolines of liquid water mixing ratio in white, red, and blue, respectively. (b) $\Delta \theta_{e}$ (K; shading), identified cold pools (black contours), moist patches (blue contours), and clouds (red contours). (c) Vertical velocity $\left(\mathrm{m} \mathrm{s}^{-1}\right)$ at a height of $35 \mathrm{~m}$ and liquid water path (blue). The white line indicates the cross section shown in (a) with the two positions A and B. All pictures show the WET simulation at 1400 LST in a $65 \times 65 \mathrm{~km}^{2}$ large subpart of the domain. 

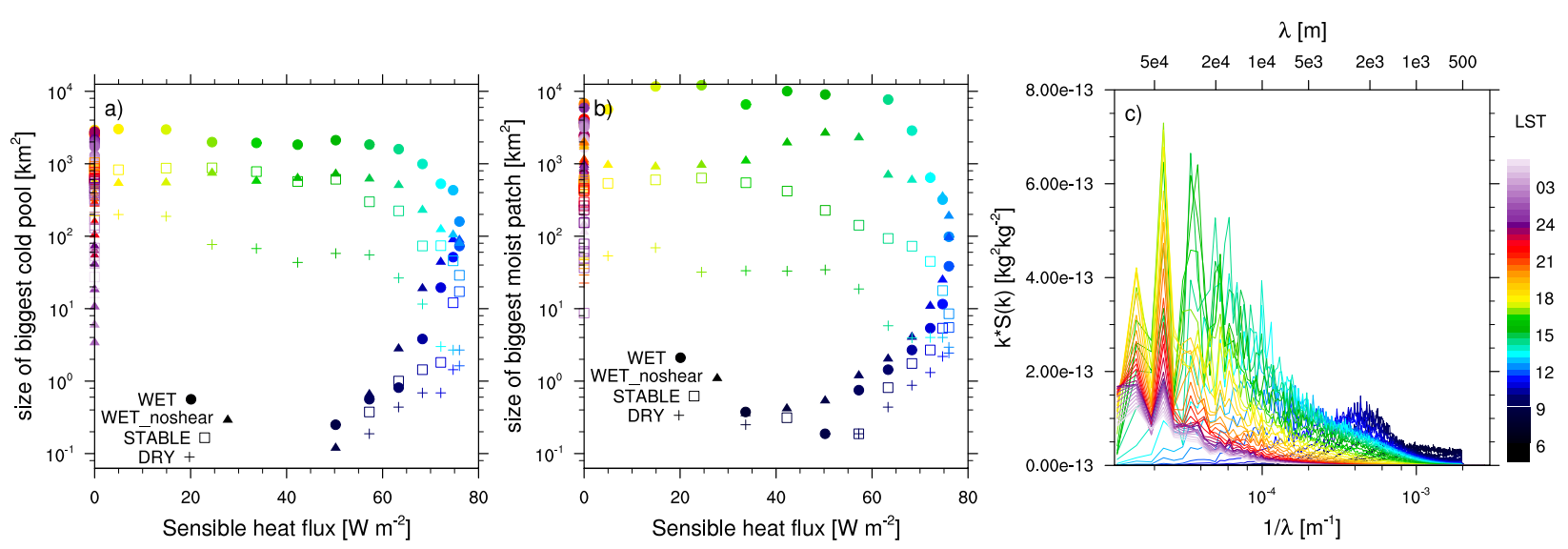

FIG. 5. (a) Size of biggest cold pool $\left(\mathrm{km}^{2}\right)$ and (b) size of biggest moist patch $\left(\mathrm{km}^{2}\right)$ as function of domain-mean surface sensible heat fluxes $\left(\mathrm{W} \mathrm{m}^{-2}\right)$ for the set of simulations. (c) Power-spectral density of the water vapor mixing ratio in the WET simulation. The spectra are computed performing a two-dimensional Fourier transformation on the data on each level from the surface up to a height of $525 \mathrm{~m}$ and subsequently averaging over the spectra. The color of the markers or lines, respectively, indicates the time of the simulations (LST).

sensible heat flux is used as an indicator for the production of turbulence by buoyancy. The increase in sensible heat flux following the diurnal cycle in incoming radiation cannot explain the observed enlargement of the cold pools and moist patches with time. First of all, there is a sudden increase of the sizes when sensible heat fluxes are already at their apex. Second, the heat fluxes are similar in all the simulations whereas both moist patches and cold pools show pronounced differences between the simulations. The same is true for simpler measures of variability such as, for example, the standard deviations of temperature and moisture. These measures follow the rain rate rather than the surface heat fluxes. It should be noted that cold pools and moist patches identified in the morning do, presumably, not originate from rain evaporation but are formed by turbulence. Fourier analysis of the total water vapor mixing ratio over the lowest $525 \mathrm{~m}$ also shows the appearance of a distinct spectral peak that grows upscale with time as soon as significant precipitation sets in (Fig. $5 \mathrm{c})$. Formation of larger-scale structures through cold pools provides an explanation for this change in the characteristic length scale of the boundary layer.

\section{b. Developing cold pools}

Figure 6 documents the time evolution of cold pools in terms of their maximum $\Delta \theta_{e}$ and size over the diurnal cycle. The focus is first on the cold pools with maximum $\Delta \theta_{e}$. As will be shown later, they are linked to the largest cold pools and largest clouds that are then more likely to transition and produce strong precipitation. Focusing on the four continental simulations first, the overall evolution
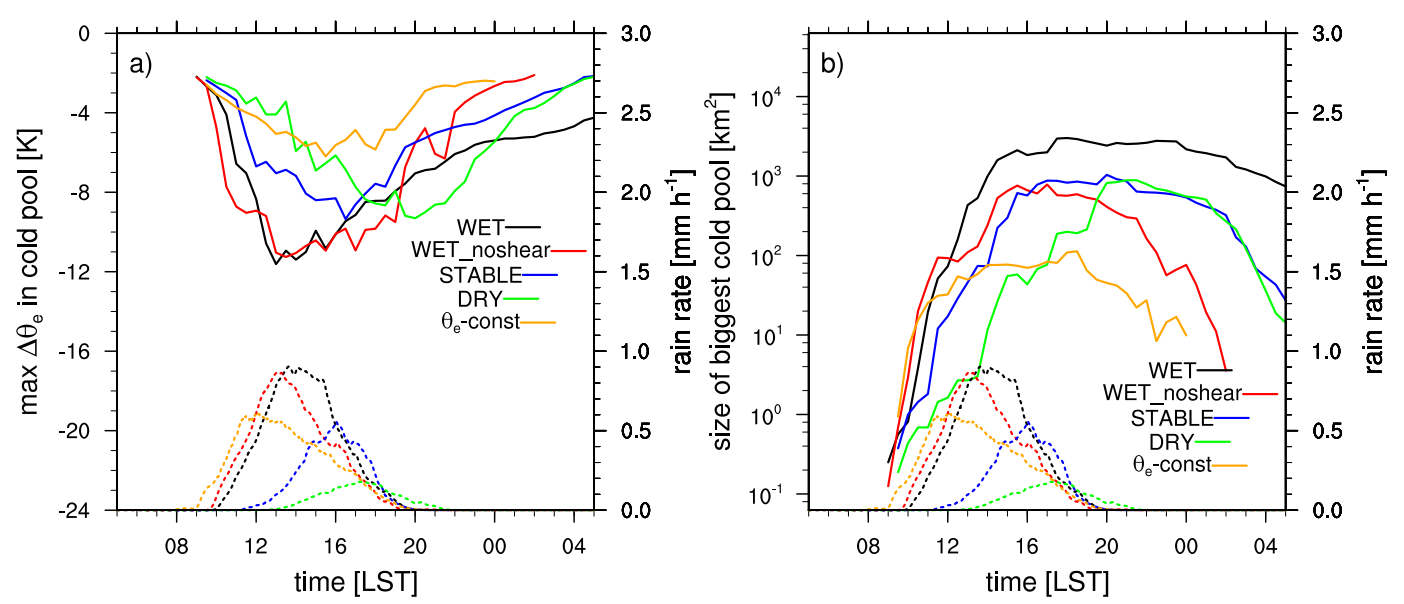

FIG. 6. Diurnal cycle of (a) $\Delta \theta_{e}$ in cold pools and (b) size of biggest cold pool for the set of simulations. The dashed lines indicate the domain-mean precipitation rate $\left(\mathrm{mm} \mathrm{h}^{-1}\right)$. To compute $\Delta \theta_{e}$, the largest temperature perturbation found within all cold pools is picked at each time step. 

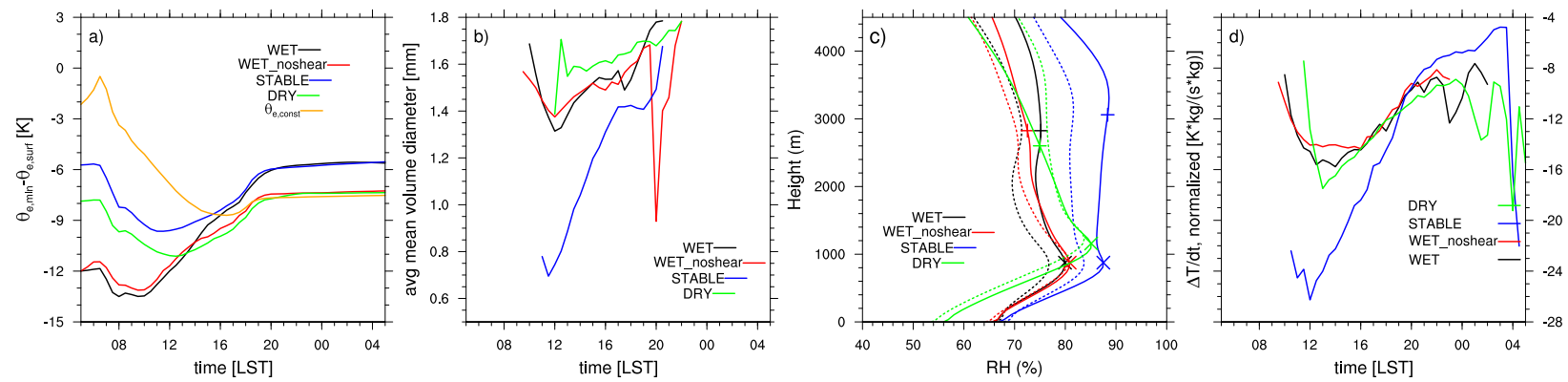

FIG. 7. (a) Difference between the domain-mean value of $\theta_{e \text {, min }}$ and $\theta_{e, \text { surf. }}$ (b) Diurnal cycle of the mean volume diameter (mm) of the rain at cloud base averaged over all rainy points for the set of simulations. (c) Relative humidity (\%) at 1400 (solid) and 1700 (dashed) LST for the set of simulations. Crosses indicate the cloud base (determined as the first level where the domain-mean liquid water content exceeds $10^{-6} \mathrm{~kg} \mathrm{~kg}^{-1}$ ) and the horizontal line the $0^{\circ} \mathrm{C}$ level of the simulations. (d) Diurnal cycle of the temperature tendency resulting from microphysics integrated over the subcloud layer normalized by the precipitation amount (the sum of the rain, snow, graupel, and hail mixing ratios) integrated over the subcloud layer averaged over all rainy points for the set of simulations.

appears similar in all simulations. Cold pools have a small $\Delta \theta_{e}$ and remain small in all simulations until 1000 LST. Since no significant precipitation is detected, this hints at a turbulent field under Rayleigh-Bénard convection. As soon as precipitation starts, cold pools exhibit a larger $\Delta \theta_{e}$ and begin to expand radially and to grow in size. The $\theta_{e}$ depression deepens in connection with precipitation and becomes thus substantially stronger in WET and WET_NOSHEAR than in STABLE or DRY. The maximum $\Delta \theta_{e}$ reaches values as low as $-12 \mathrm{~K}$ in WET but remains above $-9 \mathrm{~K}$ in STABLE or DRY. In WET the depression in $\theta$ attains values of $-4 \mathrm{~K}$ and the maximum pressure increase is roughly $1 \mathrm{hPa}$ (not shown). For comparison these values are in the lower range of values observed for mesoscale convective systems over land [see Engerer et al. (2008), their Fig. 4 and Table 2].

The sizes of the largest cold pools $A_{\mathrm{cp}}$ (Fig. 6b) grow continuously until $\sim 1800$ LST and shrink slightly thereafter. The time evolution of the size of the cold pools, especially the difference between the simulations, seems to recall the $\Delta \theta_{e}$ evolution. The growth is fastest in WET_NOSHEAR until 1200 LST and slower in STABLE and DRY. In DRY, the maximum extent is reached past 2200 LST. In the evening, when precipitation ceases in WET_NOSHEAR, both STABLE and DRY show larger sizes, in line with the precipitation signal. The relationship between cold pools and precipitation is ambiguous. On the one hand, the cold-pool properties depends on evaporation and thus rain rate (see below). On the other hand and as documented in the following, cold pools help the formation of clouds and rain.

The differences in $\Delta \theta_{e}$ between the simulations can be explained in different ways. First of all they reflect the differing vertical $\theta_{e}$ profiles and especially the difference between the minimum value of $\theta_{e}\left(\theta_{e, \min }\right)$ and its value at the surface $\left(\theta_{e \text {,surf }}\right)$. Downdrafts will carry the low $\theta_{e}$ values into the subcloud layer influencing the depth of the cold pools. The difference $\theta_{e, \min }-\theta_{e \text {,surf }}$ is largest for WET and WET_NOSHEAR and smallest in STABLE until 1400 LST (see Fig. 7a). Past 1400 LST when active convection redistributes moisture in WET, $\theta_{e \text {,min }}-\theta_{e \text {,surf }}$ decreases markedly. Second, during the deepening phase of convection the origin height of the downdrafts $z_{\text {orig }}$ and thereby $\Delta \theta_{e}$ strongly depends on the depth of the clouds, at least until they reach $z_{\min }$, the height of $\theta_{e, \min }$. In WET and WET_NOSHEAR, clouds are again considerably deeper than in DRY or STABLE at the same time. It is beyond the scope of this paper to investigate the exact origin height or to elucidate their generating mechanisms. During the transition we expect higher $z_{\text {orig }}$ for clouds that are already deeper. The $z_{\text {orig }}$ will move upward until reaching $z_{\min }$ where it should then remain (see also section 4). This is further confirmed by performing a simulation with a profile that features a constant value of $\theta_{e}=326 \mathrm{~K}$ in the vertical and a relative humidity of $95 \%$. The wind profile is equal to the one in WET, STABLE, and DRY. This hypothetical sounding resembles the limit of a very wet atmosphere where downdraft and cold-pool formation should be at a minimum. The simulation is termed $\theta_{e, \text { const }}$ and shown in orange in Fig. 6 and Fig. 7a. Owing to problems with the interactive radiation scheme this simulation was run with a constant, spatially homogeneous cooling rate of $-2 \mathrm{~K} \mathrm{day}^{-1}$. Even though rain rates are comparable to STABLE and the cloud development even stronger than in WET, cold pools are less pronounced and remain smaller in this simulation. This confirms the notion that downdrafts and thereby the vertical distribution of $\theta_{e}$ play a major role for the cold-pool characteristics.

Second, as elaborated in Kamburova and Ludlam (1966) and Srivastava (1985) with respect to the evaporation of rain, an intense rainfall rate, a lapse rate close to the dry adiabat, and a small raindrop size are all beneficial to the formation of strong downdrafts and 
thus large $\Delta \theta_{e}$. The rain amount sampled over the rainy locations is largest in WET and WET_NOSHEAR and much smaller in DRY. Concerning the lapse rate of the environment, DRY lies closest to the dry adiabat, whereas the profile is steeper in STABLE and even steeper in WET and WET_NOSHEAR (not shown). Moreover, the layer where evaporation will potentially occur is deepest in DRY, giving an extra increase in evaporation. The effect due to raindrop size indicates that rain drops are largest in DRY and smallest in STABLE (Fig. 7b). Thus, evaporation should be easiest in STABLE.

Finally, evaporation is easier in a dry environment but, if frozen hydrometeors are present, melting will occur faster at higher relative humidities (Srivastava 1985). The relative humidity below the melting level is shown in Fig. 7c. Even though the relative humidity is smaller in DRY than in the other simulations in the initial conditions, STABLE and DRY show higher values of relative humidity than WET and WET_NOSHEAR at the times investigated between $800 \mathrm{~m}$ and the melting level. This should yield a faster melting in STABLE and DRY and foster the formation of stronger downdrafts. In the subcloud layer evaporation of rain should be facilitated in DRY where it is drier. Investigating the actual temperature tendency from the microphysics routine normalized by the precipitation amount (the sum of rain, snow, graupel, and hail) both integrated over the subcloud layer (see Fig. 7d) reveals the largest normalized tendencies for STABLE until 2000 LST and a slightly larger tendency in DRY than in WET and WET_NOSHEAR. Hence, the evolution of $\Delta \theta_{e}$ as displayed by Fig. 6 is mainly dominated by the intensity of the rainfall rate for a given $\theta_{e \text {,min }}-\theta_{e \text {,surf }}$. The lapse rate, drop size, and melting effects that would yield a stronger temperature depression for DRY and STABLE are outweighed by the larger rainfall rates in WET and WET_NOSHEAR. This offset of enhanced evaporation in a drier atmosphere by stronger rain rates in a wet atmosphere has also been recognized in squall-line simulations by James and Markowski (2010). As pointed out in Bryan and Morrison (2012) the specific choices for the formulation of microphysical processes can potentially influence the results considerably.

So far the focus has been on the largest and deepest cold pools as they set the maximum length scale in the subcloud layer. To get a feeling for the full set of coldpool characteristics the distribution of the cold-pool sizes is given in Fig. 8 for two selected time steps. There is a large number of shallow and small cold pools and a small number of deep and large cold pools. The probability density distribution (pdf) approximately follows a power law with a scale break (i.e., a change of slope) at
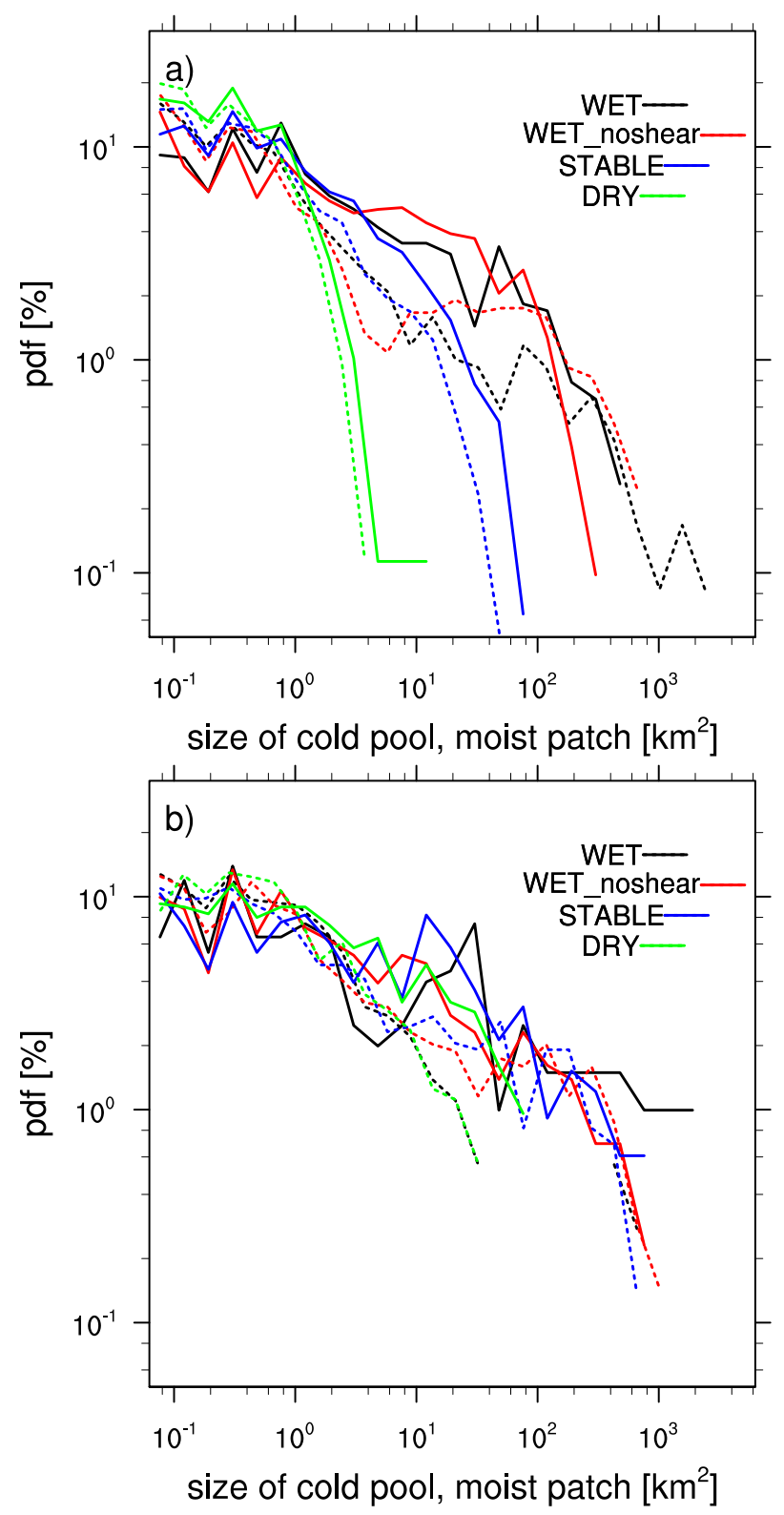

FIG. 8. Probability density function of the size of the cold pools (solid line) and the size of the moist patches (dashed line) at (a) 1400 LST and (b) 1700 LST.

larger scales $\left[O\left(100 \mathrm{~km}^{2}\right)\right]$. The differences between the simulations, indeed, mostly lie in the bigger cold pools where DRY and STABLE stay behind, that is, have fewer big cold pools. For STABLE this is true especially at the earlier time step considered, whereas in DRY the largest cold pools are absent even at 1700 LST. For any parameterization scheme representing the effects of cold pools on the developing convection it is thus essential to represent those large cold pools (see section 4). A comparable picture emerges for the pdf of $\Delta \theta_{e}$ (not shown). It should furthermore be noted that the temperature 

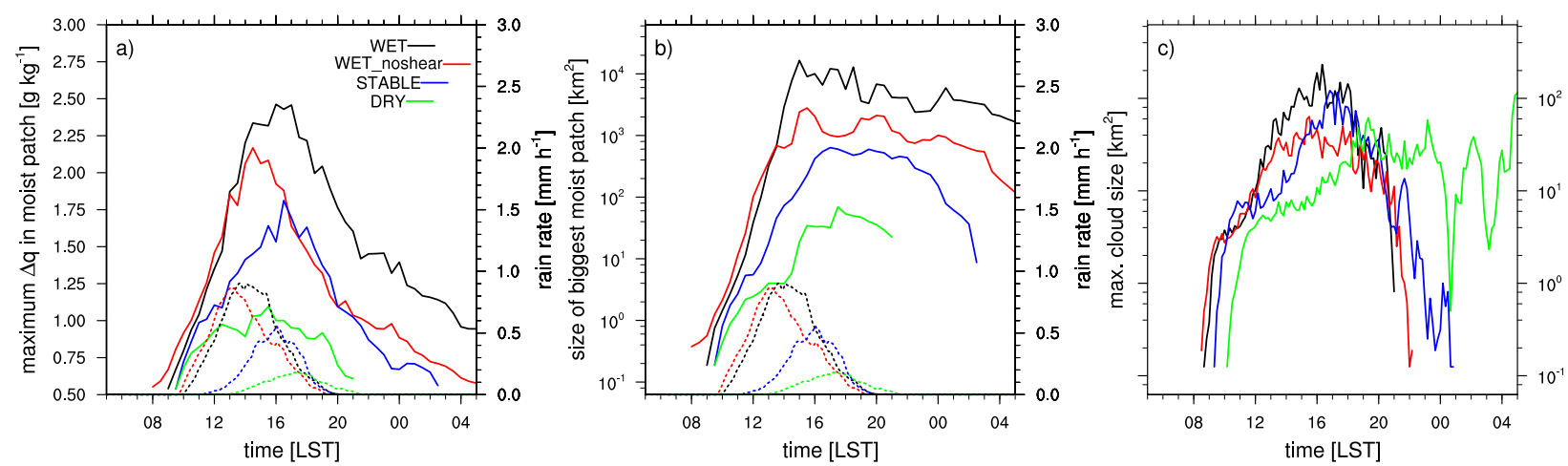

FIG. 9. Diurnal cycle of (a) maximum $\Delta q$ in moist patch and (b) size of biggest moist patch for the set of simulations. The dashed lines indicate the domain-mean rain rate $\left(\mathrm{mm} \mathrm{h}^{-1}\right)$. For $\Delta q$ the maximum perturbation present in all moist patches is picked at each time. (c) Diurnal cycle of maximum cloud size for the set of simulations.

variability within each cold pool is large (with values between $-2 \mathrm{~K}$ and the minimum value encountered).

Different mechanisms affecting the evaporation and melting of hydrometeors in the conducted simulations have been documented in this section. However, the resulting and basic cold-pool behavior remains very similar, even though the cold-pool sources might differ. In WET and WET_NOSHEAR the occurring cold pools are simply deeper and thus become larger, but the basic property of a temperature and moisture depression that spreads in time remain the same. These differences in the largest cold-pool population are nevertheless central to understand the precipitation evolution in the different simulations.

\section{c. Developing moist patches and their influence on cloud size}

Similar to the cold-pool evolution in Fig. 6, Figs. 9a and $9 \mathrm{~b}$ show the evolution of the moist patches. They are characterized in terms of the maximum $\Delta q$ and size. Here $\Delta q$ is largest for WET followed by WET NOSHEAR and smaller in STABLE and DRY. Wind shear induces a larger $\Delta q$ with a peak shifted to later times as compared to WET_NOSHEAR. The evolution of $\Delta q$ closely follows the surface rain rate and occurs concurrent with $\Delta \theta_{e}$.

The size of the moist patches $A_{\mathrm{mp}}$ (Fig. 9b) expands in all simulations. The slope in Fig. 9b is steeper in WET and WET_NOSHEAR and shows a behavior akin to the rain rate and to the cold-pool size shown in Fig. 6b. The maximum extension of the moist patches is reached at about the same time as for the cold pools and a slight shrinking is observed thereafter. Wind shear increases the size of moist patches, whereas moist patches are again smaller and less pronounced in STABLE and smallest in DRY. The difference originating from the wind shear can be understood by multiple factors. First of all, the size of the area where evaporation occurs is larger with the shear. The overlap between the area of evaporation and the dry area inside the cold pool is also larger in WET_NOSHEAR before 1200 LST and larger in WET thereafter. Wind shear finally distorts the cold-pool wake leading to a stronger head on the upstream side of the density current. Past 1600 LST, when larger cold pools are observed in STABLE than in WET_NOSHEAR, moist patches show a distinct behavior in STABLE. The same is true for DRY past 2000 LST.

The high level of agreement between rain rate and moist patches gives further confidence that the formation of moist patches is linked to cold-pool activities. The strong link between cold-pool size, moist-patch size, and precipitation evolution is evident from Figs. 6 and 9 and from the comparison of the different simulations. The distribution of the moist-patch sizes is moreover displayed together with the distribution of cold-pool sizes in Fig. 8. Although a direct mapping of a specific cold pool with a specific moist patch does not exist as multiple cold pools share common moist patches, the statistical distributions show a comparable scaling behavior. In WET and WET_NOSHEAR largest moist patches are slightly larger than the biggest cold pools whereas the number of moist patches of intermediate size is decreased. For both cold pools and moist patches, their size is not only dependent on the precipitation amount but also on their age. During the afternoon they are larger than in the morning for the same rain rate owing to the spreading and their generally older age. For the perturbation in temperature $\left(\Delta \theta_{e}\right)$ and moisture $(\Delta q)$ on the other hand, the important factor are the characteristics of the downdraft, which differ only little between the morning and the afternoon (not shown). It should furthermore be noted that the exact sizes are subject to the choice of threshold in the definition of the cold pools and moist patches. Although the offset between moist patches and 

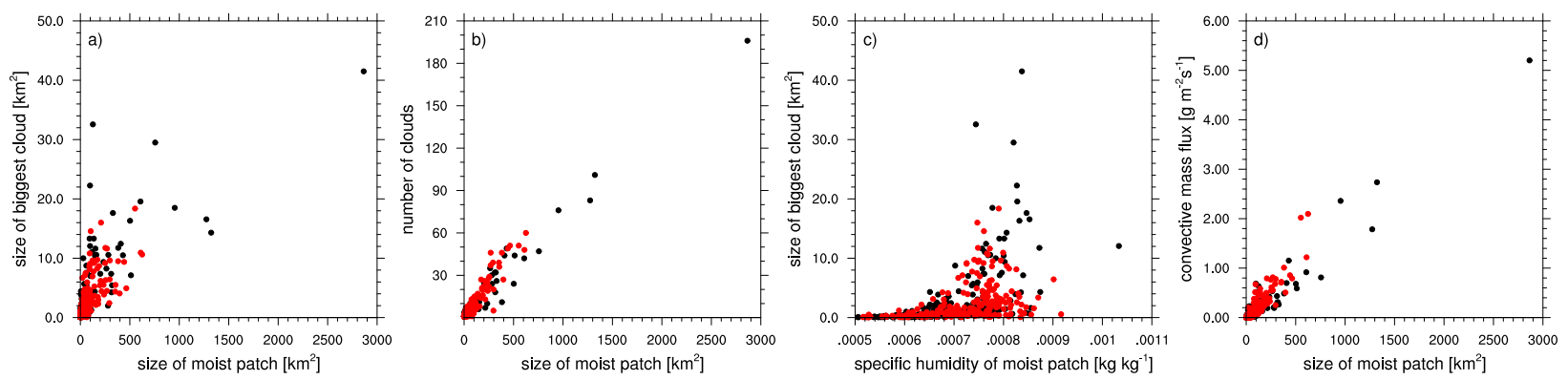

FIG. 10. (a) Size of the biggest cloud that is found in each moist patch and the size of the respective moist patch, (b) number of clouds that is found in each moist patch and the size of the respective moist patch, (c) mean specific humidity of the moist patch and the size of the biggest cloud on the moist patch, and (d) cloud-base convective mass flux and the size of the respective moist patch for WET (black) and WET_NOSHEAR (red) at 1400 LST.

cold pools might vary, the sizes $A_{\mathrm{cp}}$ and $A_{\mathrm{mp}}$ remain proportional to each other. This is linked to the similar shape of their size distributions and that the ratio between small and large cold pools and moist patches remains approximately constant. It is not clear a priory why all simulations exhibit moist patches and colds pools of equal size. This is the subject of further investigation using particle tracking.

Our principal goal is to understand the formation of wider clouds through cold-pool dynamics. Thus the size of the biggest cloud in the domain is illustrated in Fig. 9c. The evolution is similar in all simulations and akin both to the precipitation and moist-patch evolution. First clouds in the morning are small. During the deepening phase of convection, cloud sizes grow. The maximum size is reached about $1 \mathrm{~h}$ past the maximum rain rate at the surface. This is also the point in time when cloud tops are highest. The notion that the deepest clouds feature the widest cloud bases has been reported in numerous studies (e.g., Grabowski et al. 2006; Böing et al. 2012) and can be understood by the reduced lateral entrainment rates. Key to note is that the development of the maximum cloud size occurs in close agreement with the size of the biggest moist patch in the domain (see Fig. 9b). Whenever the size of the moist patch increases during the transition phase, the cloud size increases simultaneously. Likewise, the discrepancy between the simulations in terms of moist-patch sizes reflects itself in differing cloud sizes between the simulations. These differences between the simulations reflect themselves mostly in the largest clouds of the distribution. The small clouds of the population are present in all simulations, whereas clouds as large as, for example, $200 \mathrm{~km}^{2}$ will only occur in WET. In the decaying phase of convection clouds become smaller again, whereas the moist patches live on and the agreement between moist patch and cloud size begins to break down.
To further nail down the influence of the accumulation of moisture in specific regions on the development of clouds and convection, the relation between the biggest cloud found on each of the moist patches and the size of the patch is shown in Fig. 10a. The figure shows the WET and WET_NOSHEAR simulations at 1400 LST and a comparable picture emerges for different time steps as well as simulations. For a big cloud to form, there must be a large area with increased moisture. The bigger the moist patch, the more clouds will moreover be found on it (Fig. 10b). This finding states more or less that the density of clouds on the moist patch is constant. The connection between the humidity content of the moist patch and its biggest cloud is shown in Fig. 10c. Instead of the cofluctuation seen in Fig. 10a, it is rather an intermediate value of $\Delta q$ that leads to the biggest clouds. The largest clouds do not form on the moist patch featuring the highest moisture excess. This is especially visible in WET_NOSHEAR where the largest cloud is found for a moisture excess of $0.8 \mathrm{~g} \mathrm{~kg}^{-1}$. There is however a limiting behavior, as in order to form a large cloud there must be sufficient moisture available. Thus, it is not the amplitude of the moisture anomaly but rather its size that is important for the formation of larger clouds. The impact of the size of the moist patch onto the further development of convection is finally illustrated by analyzing the cloud-base convective mass flux in Fig. 10d. The convective mass flux $M=\rho_{m} \sigma w_{\text {up }}$ is determined by multiplying the air density averaged over the moist patch $\rho_{m}$ by the vertical velocity $w_{\text {up }}$ averaged over all spots within the moist patch where the vertical velocity exceeds $1 \mathrm{~m} \mathrm{~s}^{-1}$ and by multiplying by the cloud fraction $\sigma$. Thereby $\sigma$ is the number of cloudy updrafts within the moist patch divided by the total points in the domain. As there are more and larger clouds on larger moist patches, the cloud fraction increases and thus also the convective mass flux. 

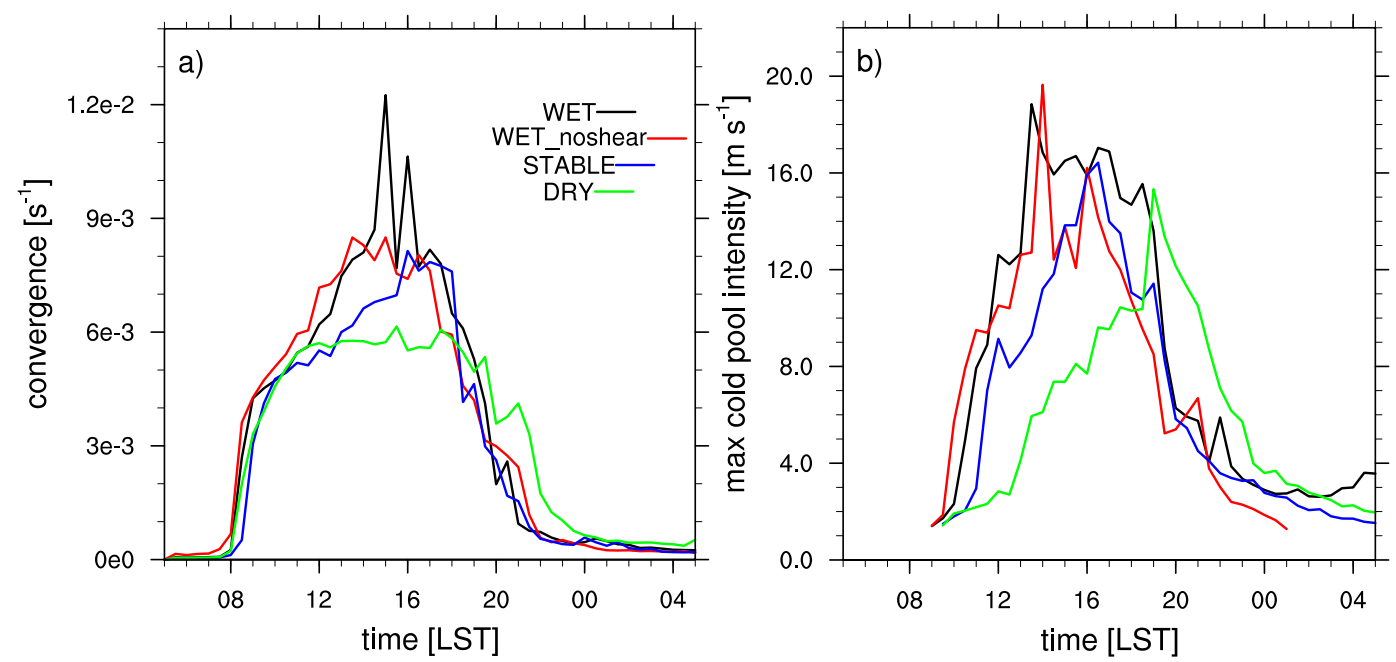

FIG. 11. (a) Maximum convergence $\left(\mathrm{s}^{-1}\right)$ in the domain averaged over the lowest $525 \mathrm{~m}$ and (b) maximum cold-pool intensity $\left(\mathrm{m} \mathrm{s}^{-1}\right)$.

The presence of multiple clouds on each moist patch is entrainment-wise additionally beneficial. Böing et al. (2012) listed two hypothesis in order to explain why the cloud depth is mostly uncorrelated with the thermodynamic properties of the subcloud layer: the "nearenvironment" hypothesis, where multiple clouds tend to form in the near environment at the intersection of gust fronts, allowing them to become larger at cloud base and the "time-scale hypothesis," where numerous updrafts will repeatedly form at a similar location. Our findings support their near-environment hypothesis in that moisture is accumulated in regions where cold pools intersect, favoring the generation of wider clouds. In our simulations stronger rain rates yield bigger cold pools and moist patches, which, in summary, lead to the formation of bigger clouds. As known, these bigger clouds yield deeper clouds, which explains the often-mentioned link between cold pools and deeper clouds. The effect of cold pools aggregating moisture is consistent with earlier results by Addis et al. (1984) and Tompkins (2001b) for the organization of deep convection over tropical ocean and Seifert and Heus (2013) for shallow convection. It is very interesting to see that this aspect also occurs in simulations over land independently of the atmospheric conditions as well as when the time to aggregate is much shorter. This is of interest for the design of parameterizations (see section 4).

\section{d. Convergence and dynamical triggering}

To compare the dynamical effects of the cold pools in the different simulations, the maximum convergence averaged over the lowest $525 \mathrm{~m}$ of the atmosphere is documented in Fig. 11a. Convergence increases already from 0800 LST onward and is first largest in WET_NOSHEAR.
During the time of maximum precipitation convergence in both WET and WET_NOSHEAR is similar, whereas a delayed increase can be observed in STABLE. Most importantly the time of maximum convergence occurs at the same time in WET, WET_NOSHEAR, and DRY, whereas all the other properties considered previously showed a time lag between WET/WET_NOSHEAR and STABLE/DRY.

For organized convective systems the cold-pool intensity $c_{i}$ is a measure that relates the maximum possible propagation speed of the gust front to the height of the cold-pool $H_{\mathrm{cp}}$. The latter is defined as the height of the level of neutral buoyancy over a cold pool [see Rotunno et al. (1988)]:

$$
c_{i}=\sqrt{2 \int_{0}^{H_{\mathrm{cp}}}(-B) d z},
$$

where $B$ is the buoyancy. The respective value $H_{\mathrm{cp}}$ for the simulations is determined by first computing the three-dimensional buoyancy field and then searching for the level where buoyancy changes its sign from negative to positive values above each cold pool.

Figure $11 \mathrm{~b}$ shows values of $c_{i}$ for the set of simulations. In the computation the maximum value of $c_{i}$ in the domain is selected. The evolution of $c_{i}$ shows similarities with the evolution of the cold-pool depth in Fig. 6a. Here $c_{i}$ is largest in WET, slightly smaller if the shear is removed, and especially during the morning hours smaller for DRY. STABLE mostly shows a lag in time. This is consistent with the precipitation evolution in the different simulations. For comparison, the calculated $c_{i}$ values are smaller than typically observed for squall lines for which 
values of more than $30 \mathrm{~m} \mathrm{~s}^{-1}$ have been reported [e.g., Bryan and Parker (2010) and references therein].

Summarizing, we can state that cold pools act both through a separation of the moisture field with formation of moister areas and an enhanced vertical lifting along the leading edge of the cold pool. These effects are difficult to disentangle but both of them are present in all of the conducted simulations. There is no basic different mechanism in which the new convective cells are triggered in the different simulations, but the cold pools and resulting moist patches become larger and more pronounced in the simulations with more precipitation. These simulations also exhibit larger convergence and higher cold-pool intensities. By the occurrence of these more pronounced cold pools a positive feedback is sustained, whereby wider clouds form that in their turn are less affected by entrainment, grow deeper, and produce more precipitation. This leads to deeper, more intense, and larger cold pools, larger moist patches, and larger clouds with higher convective mass fluxes, closing the feedback loop.

\section{Pathway to a parameterization}

Several successful attempts have been undertaken to include the effects of cold pools into parameterization schemes (e.g., Qian et al. 1998; Mapes 2000; Rio et al. 2009; Grandpeix and Lafore 2010; Hohenegger and Bretherton 2011). In these approaches the focus has been on the wakes of the cold pools and the associated dynamical triggering. Judging from the results of section $3 \mathrm{c}$ it seems worth including the role of a moisture aggregation. The underlying idea is that cold pools, through moisture aggregation and the production of bigger clouds, reduce the entrainment rate. The latter is often viewed as inversely proportional to the cloud radius. Hence, starting from a high entrainment rate in the morning, the formation of cold pools helps reducing the entrainment rate as time proceeds. Thereby, the development of convection is delayed in the first place and its peak in the afternoon is prolonged. This approach is akin to the procedure proposed in Stirling and Stratton (2012), where the entrainment rate for the early stages of developing convection over land was linked to the lifted condensation level, taken as a surrogate for cloud radius. The approach of including the effect of cold pools on the widening of clouds bears similarities with parameterizing one aspect of a parameter characterizing convective organization, as, for example, the "org" parameter defined in Mapes and Neale (2011). They indicated that the organization of convection affects cloud base, entrainment, and closure values and argued for the use of a prognostic equation for org. The size effect of cold pools described in section 3 may be viewed as one of the mechanisms controlling the evolution of org. Hohenegger and Bretherton (2011) employed the surface precipitation as a predictor for the horizontal standard deviation of specific humidity, which in turn feeds back onto the mean updraft moist static energy as well as on the entrainment rate. Our analysis allows a more physically based derivation of the effect of moisture aggregation on the cloud size and thereby entrainment rate via cold-pool effects.

As a starting point the size $A_{\mathrm{cp}}$ (area) of the cold pools is predicted. The latter relates to the depression of $\theta_{e}$ in the cold pools $\Delta \theta_{e}$ through the propagation speed [coldpool intensity; see Eq. (2)] of the wakes. As elaborated in section $3 \mathrm{~b}$ the vertical profile of $\theta_{e}$ is an important ingredient to predict $\Delta \theta_{e}$. The difference between $\theta_{e \text {,surf }}$ and the $\theta_{e}$ value at the origin height of the downdraft $z_{\text {orig }}$ is used as an approximation:

$$
\Delta \theta_{e}=\beta\left[\theta_{e}\left(z_{\text {orig }}\right)-\theta_{e, \text { surf }}\right],
$$

where $z_{\text {orig }}$ is approximated to lie between the cloudbase $z_{\mathrm{cb}}$ and the cloud-top $z_{\mathrm{ct}}$, or at the height $z_{\min }$ of the minimum value of $\theta_{e}$ if $z_{\text {orig }}$ lies above $z_{\min }$; that is,

$$
z_{\text {orig }}=\min \left[z_{\mathrm{cb}}+\frac{1}{3}\left(z_{\mathrm{ct}}-z_{\mathrm{cb}}\right), z_{\mathrm{min}}\right] \text {. }
$$

Investigating mass-flux profiles it is apparent that downdrafts from shallower clouds experience more dilution on their way downward than downdrafts originating from deeper clouds, indicating that downdrafts from deeper clouds are more saturated (not shown). This is taken into account by specifying a timedependent dilution factor for the downdraft $\beta$ in Eq. (3) that will reach 1 (meaning no dilution) for cloud tops reaching a height of $8 \mathrm{~km}$ :

$$
\beta=\min \left[1, \frac{\left(z_{\mathrm{ct}}-z_{\mathrm{cb}}\right)}{8000 \mathrm{~m}-z_{\mathrm{cb}}}\right] .
$$

Note that, if a convection scheme already provides an explicit downdraft formulation, Eq. (3) is not needed.

Equation (3) is tested using the simulation results. The domain-mean values of the simulations are used as a surrogate for a gridpoint value of a hypothetical lowresolution model. The heights $z_{\mathrm{ct}}, z_{\mathrm{cb}}$, and the vertical $\theta_{e}$ profile are taken from these domain averages to compute $\Delta \theta_{e}$ using Eq. (3). Figure 12a shows the computed values of $\Delta \theta_{e}$. The curves for WET, WET_NOSHEAR, STABLE, and DRY should be compared to the corresponding curves in Fig. 6a. Figure 12 also includes the curve for the OCEAN simulation (see section $2 b$ ) as a further test. Comparison of the curves indicates that 

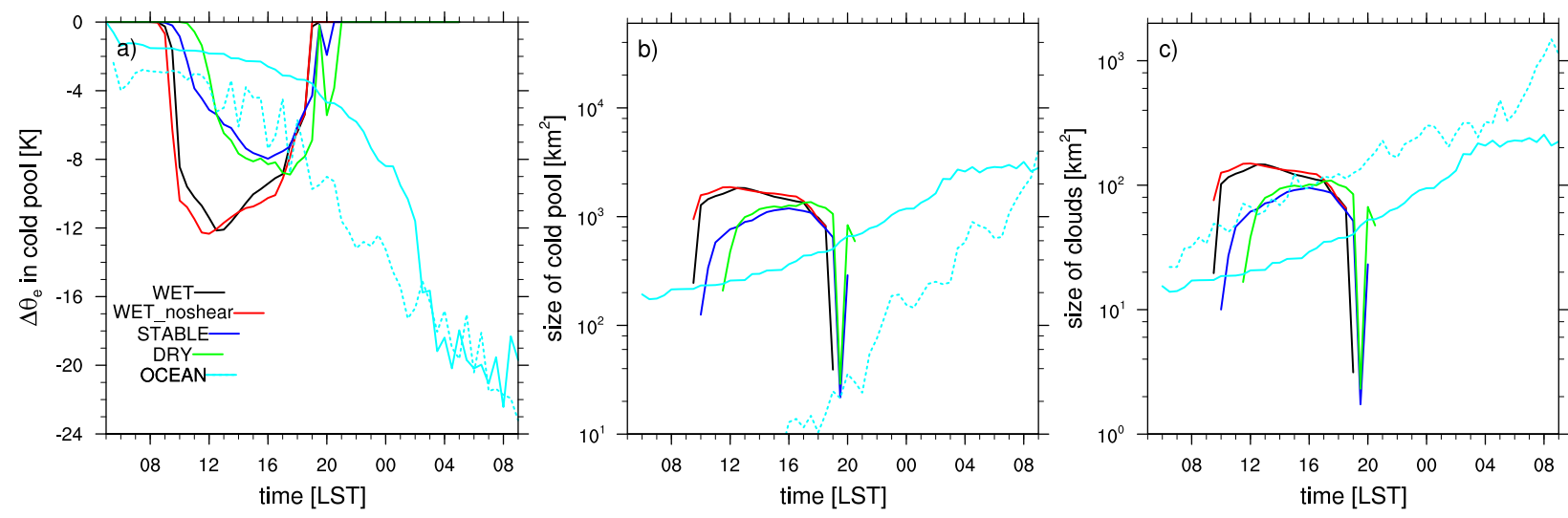

FIG. 12. Parameterized values of (a) maximum $\Delta \theta_{e}$, (b) size of biggest cold pool, and (c) size of biggest cloud. Solid lines indicate the values received from the parameterization whereas the cyan dashed lines indicate data from the cloud-resolving model for OCEAN.

Eq. (3) is able to approximately capture the magnitude of the perturbation but also the timing; that is, the time the minimum $\Delta \theta_{e}$ is attained for the different simulations. Note that using simpler measures to predict $\Delta \theta_{e}$ like the surface rain rate results in a too early increase in $\Delta \theta_{e}$. The same is true when neglecting the dilution factor $\beta$.

Knowledge of $\Delta \theta_{e}$ allows computation of the coldpool intensity $c_{i}$ [cf. Eq. (2)]:

$$
c_{i}=\sqrt{\left(z_{2}-z_{1}\right) g \frac{-\Delta \theta_{e}}{\theta_{e, \text { surf }}}},
$$

where $g$ is the acceleration of gravity. The buoyancy is hereby approximated by $g\left(-\Delta \theta_{e} / \theta_{e \text {,surf }}\right)$, whereas the depth of the cold pool is set to $z_{2}-z_{1}=525 \mathrm{~m}-35 \mathrm{~m}$ in agreement with our criteria used to detect cold pools. Multiplying $c_{i}$ by the propagation time and assuming circular cold pools finally yields the cold-pool area $A_{\mathrm{cp}}$ :

$$
A_{\mathrm{cp}}=\pi\left\{c_{i} \min [\Delta t,(1800 \mathrm{~s})]\right\}^{2} .
$$

The time since the first precipitation is used as a time measure for the spreading of the cold pool $\Delta t$. The time is however limited to an upper value of $0.5 \mathrm{~h}$. This upper limit to the propagation time yields best results. For a longer time span, an average cold-pool intensity would be required. Equation (7) should be understood as a proof of concept. In theory, a complex parameterization for the development of cold pools should be used [see, e.g., Grandpeix and Lafore (2010)]. Figure 12b shows the evolution of $A_{\mathrm{cp}}$ as predicted using Eqs. (3)(7). Despite the different simplifications, a comparison of Fig. 12b with Fig. 6b reveals a good level of agreement. The different time evolution and magnitude between the simulations is reproduced. For OCEAN the values for the sizes of the cold pools are considerably overestimated in the beginning of the simulation. This stems from the very large $\Delta \theta_{e}$. The increase of the size with time is, however, reproduced.

The size of the moist patches $A_{\mathrm{mp}}$ relates to the size of the cold pools $A_{\mathrm{cp}}$ as seen in Fig. 8. The latter supports a linear relationship:

$$
A_{\mathrm{mp}}=\alpha A_{\mathrm{cp}} .
$$

In this first implementation we set $\alpha$ to 1 based on the results of Fig. 8, indicating a roughly equal size of the moist patches and the cold pools. Note that this choice is subject to the exact threshold definition in the formulation of the cold pools and moist patches (see the discussion in section 3c).

Finally, Fig. 10 can be used to give a value for the size of the biggest cloud $A_{c}$ based on $A_{\mathrm{mp}}$ :

$$
A_{c}=0.08 A_{\mathrm{mp}} \text {. }
$$

This means that the biggest clouds occupy $8 \%$ of the biggest moist patches. Figure $12 \mathrm{c}$ shows the final prediction of $A_{c}$. The agreement with Fig. 9c is encouraging. In OCEAN cloud sizes are underpredicted at the beginning of the simulation. This is in contrast to the overprediction of the cold-pool sizes noted earlier. Despite the very simple relationships employed, Eqs. (3)(9) capture the main differences in size between the simulations: largest clouds in WET, WET_NOSHEAR, smaller clouds and a time delay in DRY and STABLE, and a slower evolution and a very large $\Delta \theta_{e}$ in OCEAN. This confirms the results presented in section 3 .

\section{Summary}

This study investigated how the presence of cold pools promotes the formation and maintenance of wider and deeper clouds as a result of moisture modulations in the 
subcloud layer. Cold pools are hereby understood as a decrease of the subcloud layer $\theta_{e}$ as a result of evaporatively driven penetrative downdrafts. Special attention was given to the characteristics of the cold pools and related processes. Results were confirmed in different atmospheric conditions whereby the conducted simulations mimicked the diurnal cycle of convection over continental midlatitude areas under wet, stable, and no wind shear conditions. These results were also tested for a case of convective development over tropical oceans in a dry atmosphere.

Deep precipitating convection develops in all conducted simulations. The time evolution of the size of the convective clouds and associated precipitation goes in line with the time evolution of cold pools and related characteristics. Of particular importance for the transition and the production of strong precipitation are the characteristics of the bigger cold pools and bigger clouds. The simulations, both in terms of cloud-size distribution and cold-pool distribution only, distinguish themselves in terms of their larger clouds and cold pools.

The depression in equivalent potential temperature $\Delta \theta_{e}$ in the larger cold pools could be linked to the vertical profile of $\theta_{e}$, the origin of the downdraft, and the rain rate. In the conducted simulations cold pools exhibit a larger $\Delta \theta_{e}$ and become bigger in a wetter environment, whereas they are hampered in both a drier and more stable atmosphere. Wind shear seems to delay the deepening of clouds in the first place but later supports the formation of larger cold pools owing to a larger area of evaporation and a better overlap of the area of evaporation with the cold and dry areas. This prolongs the precipitation peak. In all simulations the size of the largest cold pools relates to $\Delta \theta_{e}$ during the transition.

Occurring cold pools are moreover characterized by a depletion of moisture. This in turn leads to an accumulation of moisture around the cold pools, which we called moist patches-a positive moisture perturbation along the edges of a cold pool that extends from the surface throughout the boundary layer. The evolution of these moist patches throughout the diurnal cycle recalls the size evolution of the cold pools. They thus become larger and hold a larger moisture perturbation in a wetter atmosphere. Most importantly new clouds form predominantly on these moist patches, with larger cloud sizes and increased convective mass fluxes for larger moist patches. Wider clouds are in turn known to be less affected by entrainment of environmental air and can thus more easily reach higher altitudes. These deeper clouds again feature stronger downdrafts and cold pools that simultaneously yields larger moist patches and, thus, even wider clouds, so a positive feedback mechanism acts. As a consequence, the transition to deep convection occurs earlier in a moist environment. The size effect, that is, that larger moist patches support larger clouds, seems more important than the moisture accumulation per se, independently of the atmospheric conditions. The largest clouds tend to occupy $5 \%-10 \%$ of the largest moist patches. A patch of a $100 \mathrm{~km}^{2}$ size supports typically 10 clouds.

The moist patches are also the locations where the wake from the density currents associated with the cold pools collide. Enhanced convergence and lifting result, favoring convective triggering. Independently of the atmospheric and surface conditions, both the size effect and the dynamical triggering seems to take place. A segregation of these two effects is difficult. Nevertheless, in a wetter environment both lifting and moisture aggregation is enhanced and the maximum intensity occurs at the same time in the diurnal cycle, whereas it is delayed otherwise. All in all, it is noteworthy that similar mechanisms are acting both over land and over ocean, dry and wet environments, stable and unstable, with wind shear and without wind shear, as well as for shallow and deep convection.

Whereas newer convective parameterizations include the effect of dynamical triggering by cold pools, the size effect of moisture aggregation on clouds is generally neglected. A way is proposed and tested to parameterize this latter effect. The size of developing clouds is related to the size of evolving moist patches that, in turn, is parameterized based on the origin height of the downdrafts and the vertical $\theta_{e}$ profile. The cloud size is then supposed to feed back onto the entrainment rate $\varepsilon$, whereby $\varepsilon$ is inversely proportional to the cloud radius. Comparison of this simple parameterization with the simulation output shows promising results.

Acknowledgments. This study was supported by the Hans Ertel Centre for Weather Research. This research network of Universities, Research Institutes and the Deutscher Wetterdienst is funded by the BMVBS (Federal Ministry of Transport, Building and Urban Development). The supercomputer facilities at the Deutsches Klimarechenzentrum (DKRZ) are acknowledged. We thank Thijs Heus and Axel Seifert for continuous support with UCLA-LES and helpful discussions. Moreover we want to thank three anonymous reviewers for their constructive suggestions, which helped to improve the quality of the manuscript.

\section{REFERENCES}

Addis, R. P., M. Garstang, and G. D. Emmitt, 1984: Downdrafts from tropical oceanic cumuli. Bound.-Layer Meteor., 28, 23 49, doi:10.1007/BF00119455. 
Barnes, G. M., and M. Garstang, 1982: Subcloud layer energetics of precipitating convection. Mon. Wea. Rev., 110, 102-117, doi:10.1175/1520-0493(1982)110<0102:SLEOPC > 2.0.CO;2.

Bechtold, P., J.-P. Chaboureau, A. Beljaars, A. K. Betts, M. Köhler, M. Miller, and J.-L. Redelsperger, 2004: The simulation of the diurnal cycle of convective precipitation over land in a global model. Quart. J. Roy. Meteor. Soc., 130, 31193137, doi:10.1256/qj.03.103.

_ , N. Semane, P. Lopez, J.-P. Chaboureau, A. Beljaars, and N. Bormann, 2014: Representing equilibrium and nonequilibrium convection in large-scale models. J. Atmos. Sci., 71, 734-753, doi:10.1175/JAS-D-13-0163.1.

Betts, A. K., and C. Jakob, 2002: Evaluation of the diurnal cycle of precipitation, surface thermodynamics, and surface fluxes in the ECMWF model using LBA data. J. Geophys. Res., 107, 8045, doi:10.1029/2001JD000427.

Böing, S. J., H. J. J. Jonker, A. P. Siebesma, and W. W. Grabowski, 2012: Influence of the subcloud layer on the development of a deep convective ensemble. J. Atmos. Sci., 69, 2682-2698, doi:10.1175/JAS-D-11-0317.1.

Bony, S., and K. A. Emanuel, 2005: On the role of moist processes in tropical intraseasonal variability: Cloud-radiation and moisture-convection feedbacks. J. Atmos. Sci., 62, 2770-2789, doi:10.1175/JAS3506.1.

Bryan, G. H., and M. D. Parker, 2010: Observations of a squall line and its near environment using high-frequency rawinsonde launches during VORTEX2. Mon. Wea. Rev., 138, 4076-4097, doi:10.1175/2010MWR3359.1.

_ , and H. Morrison, 2012: Sensitivity of a simulated squall line to horizontal resolution and parameterization of microphysics. Mon. Wea. Rev., 140, 202-225, doi:10.1175/ MWR-D-11-00046.1.

Byers, H. R., and R. R. Braham Jr., 1949: The Thunderstorm: Report of the Thunderstorm Project. U.S. Government Printing Office, $282 \mathrm{pp}$.

Chaboureau, J.-P., F. Guichard, J.-L. Redelsperger, and J.-P. Lafore, 2004: The role of stability and moisture in the diurnal cycle of convection over land. Quart. J. Roy. Meteor. Soc., 130, 3105-3117, doi:10.1256/qj.03.132.

de Rooy, W. C., and Coauthors, 2013: Entrainment and detrainment in cumulus convection: An overview. Quart. J. Roy. Meteor. Soc., 139, 1-19, doi:10.1002/qj.1959.

Dione, C., M. Lothon, D. Badiane, B. Campistron, F. Couvreux, F. Guichard, and S. M. Sall, 2013: Phenomenology of Sahelian convection observed in Niamey during the early monsoon. Quart. J. Roy. Meteor. Soc., 140, 500-516, doi:10.1002/qj.2149.

Engerer, N. A., D. J. Stensrud, and M. C. Coniglio, 2008: Surface characteristics of observed cold pools. Mon. Wea. Rev., 136, 4839-4849, doi:10.1175/2008MWR2528.1.

Flamant, C., P. Knippertz, D. J. Parker, J.-P. Chaboureau, C. Lavaysse, A. Agusti-Panareda, and L. Kergoat, 2009: The impact of a mesoscale convective system cold pool on the northward propagation of the intertropical discontinuity over West Africa. Quart. J. Roy. Meteor. Soc., 135, 139-159, doi:10.1002/qj.357.

Fritsch, J. M., and G. S. Forbes, 2001: Mesoscale convective systems. Meteor. Monogr., No. 28, 323-358, doi:10.1175/ 0065-9401-28.50.323.

$\mathrm{Fu}$, Q., and K. N. Liou, 1993: Parameterization of the radiative properties of cirrus clouds. J. Atmos. Sci., 50, 2008-2025, doi:10.1175/1520-0469(1993)050<2008:POTRPO > 2.0.CO;2.

Grabowski, W. W., and Coauthors, 2006: Daytime convective development over land: A model intercomparison based on
LBA observations. Quart. J. Roy. Meteor. Soc., 132, 317-344, doi:10.1256/qj.04.147.

Grandpeix, J.-Y., and J.-P. Lafore, 2010: A density current parameterization coupled with Emanuel's convection scheme. Part I: The models. J. Atmos. Sci., 67, 881-897, doi:10.1175/ 2009JAS3044.1.

Hohenegger, C., and C. S. Bretherton, 2011: Simulating deep convection with a shallow convection scheme. Atmos. Chem. Phys., 11, 10389-10406, doi:10.5194/acp-11-10389-2011.

- and B. Stevens, 2013: Preconditioning deep convection with cumulus congestus. J. Atmos. Sci., 70, 448-464, doi:10.1175/ JAS-D-12-089.1.

James, R. P., and P. M. Markowski, 2010: A numerical investigation of the effects of dry air aloft on deep convection. Mon. Wea. Rev., 138, 140-161, doi:10.1175/2009MWR3018.1.

Johnson, R. H., and M. E. Nicholls, 1983: A composite analysis of the boundary layer accompanying a tropical squall line. Mon. Wea. Rev., 111, 308-319, doi:10.1175/1520-0493(1983)111<0308: ACAOTB $>2.0 . C O ; 2$

Kamburova, P. L., and F. H. Ludlam, 1966: Rainfall evaporation in thunderstorm downdraughts. Quart. J. Roy. Meteor. Soc., 92, 510-518, doi:10.1002/qj.49709239407.

Khairoutdinov, M., and D. Randall, 2006: High-resolution simulations of shallow-to-deep convection transition over land. J. Atmos. Sci., 63, 3421-3436, doi:10.1175/JAS3810.1.

Kuang, Z., and C. S. Bretherton, 2006: A mass-flux scheme view of a high-resolution simulation of a transition from shallow to deep cumulus convection. J. Atmos. Sci., 63, 1895-1909, doi:10.1175/JAS3723.1.

Lima, M. A., and J. W. Wilson, 2008: Convective storm initiation in a moist tropical environment. Mon. Wea. Rev., 136, 1847-1864, doi:10.1175/2007MWR2279.1.

Lin, Y.-L., R. L. Deal, and M. S. Kulie, 1998: Mechanisms of cell regeneration, development, and propagation within a twodimensional multicell storm. J. Atmos. Sci., 55, 1867-1886, doi:10.1175/1520-0469(1998)055<1867:MOCRDA > 2.0.CO;2.

Lothon, M., B. Campistron, M. Chong, F. Couvreux, F. Guichard, C. Rio, and E. Williams, 2011: Life cycle of a mesoscale circular gust front observed by a C-band Doppler radar in West Africa. Mon. Wea. Rev., 139, 1370-1388, doi:10.1175/2010MWR3480.1.

Mapes, B. E., 2000: Convective inhibition, subgrid-scale triggering energy, and stratiform instability in a toy tropical wavemodel. J. Atmos. Sci., 57, 1515-1535, doi:10.1175/ 1520-0469(2000)057<1515:CISSTE $>2.0$. CO $; 2$

, and R. Neale, 2011: Parameterizing convective organization to escape the entrainment dilemma. J. Adv. Model. Earth Syst., 3, M06004, doi:10.1029/2011MS000042.

Pincus, R., and B. Stevens, 2009: Monte Carlo spectral integration: A consistent approximation for radiative transfer in large eddy simulations. J. Adv. Model. Earth Syst., 1 (1), doi:10.3894/ JAMES.2009.1.1.

Qian, L., G. S. Young, and W. M. Frank, 1998: A convective wake parameterization scheme for use in general circulation models. Mon. Wea. Rev., 126, 456-469, doi:10.1175/ 1520-0493(1998)126<0456:ACWPSF > 2.0.CO;2.

Rio, C., F. Hourdin, J.-Y. Grandpeix, and J.-P. Lafore, 2009: Shifting the diurnal cycle of parameterized deep convection over land. Geophys. Res. Lett., 36, L07809, doi:10.1029/ 2008GL036779.

Ross, A. N., A. M. Tompkins, and D. J. Parker, 2004: Simple models of the role of surface fluxes in convective cold pool evolution. J. Atmos. Sci., 61, 1582-1595, doi:10.1175/ 1520-0469(2004)061<1582:SMOTRO >2.0.CO;2. 
Rotunno, R., J. B. Klemp, and M. L. Weisman, 1988: A theory for strong, long-lived squall lines. J. Atmos. Sci., 45, 463-485, doi:10.1175/1520-0469(1988)045<0463:ATFSLL>2.0.CO;2.

Schlemmer, L., C. Hohenegger, J. Schmidli, and C. Schär, 2012: Diurnal equilibrium convection and land surface-atmosphere interactions in an idealized cloud-resolving model. Quart. J. Roy. Meteor. Soc., 138, 1526-1539, doi:10.1002/qj.1892.

Seifert, A., and K. D. Beheng, 2006: A two-moment cloud microphysics parameterization for mixed-phase clouds. Part I: Model description. Meteor. Atmos. Phys., 92, 45-66, doi:10.1007/ s00703-005-0112-4.

— cipitating trade wind cumulus clouds. Atmos. Chem. Phys. Discuss., 13, 1855-1889, doi:10.5194/acpd-13-1855-2013.

Siebesma, A. P., and Coauthors, 2003: A large eddy simulation intercomparison study of shallow cumulus convection. $J$. Atmos. Sci., 60, 1201-1219, doi:10.1175/1520-0469(2003)60<1201: ALESIS $>2.0 . C O ; 2$.

Srivastava, R. C., 1985: A simple model of evaporatively driven downdraft: Application to microburst downdraft. J. Atmos. Sci., 42, 1004-1023, doi:10.1175/1520-0469(1985)042<1004: ASMOED $>2.0 . \mathrm{CO} ; 2$.

_ 1987: A model of intense downdrafts driven by the melting and evaporation of precipitation. J. Atmos. Sci., 44, 1752-1774, doi:10.1175/1520-0469(1987)044<1752:AMOIDD>2.0.CO;2.

Stevens, B., and Coauthors, 2005: Evaluation of large-eddy simulations via observations of nocturnal marine stratocumulus. Mon. Wea. Rev., 133, 1443-1462, doi:10.1175/MWR2930.1.

Stirling, A. J., and R. A. Stratton, 2012: Entrainment processes in the diurnal cycle of deep convection over land. Quart. J. Roy. Meteor. Soc., 138, 1135-1149, doi:10.1002/qj.1868.
Tompkins, A. M., 2001a: Organization of tropical convection in low vertical wind shears: The role of water vapor. J. Atmos. Sci., 58, 529-545, doi:10.1175/1520-0469(2001)058<0529: OOTCIL $>2.0 . \mathrm{CO} ; 2$.

_ 2001b: Organization of tropical convection in low vertical wind shears: The role of cold pools. J. Atmos. Sci., 58, 1650-1672, doi:10.1175/1520-0469(2001)058<1650: OOTCIL $>2.0 . \mathrm{CO} ; 2$.

Waite, M. L., and B. Khouider, 2010: The deepening of tropical convection by congestus preconditioning. J. Atmos. Sci., 67, 2601-2615, doi:10.1175/2010JAS3357.1.

Wakimoto, R. M., 1982: The life cycle of thunderstorm gust fronts as viewed with Doppler radar and rawinsonde data. Mon. Wea. Rev., 110, 1060-1082, doi:10.1175/1520-0493(1982)110<1060: TLCOTG $>2.0 . \mathrm{CO} ; 2$.

Warner, C., J. Simpson, D. W. Martin, D. Suchman, F. R. Mosher, and R. F. Reinking, 1979: Shallow convection on day 261 of GATE: Mesoscale arcs. Mon. Wea. Rev., 107, 1617-1635, doi:10.1175/1520-0493(1979)107<1617:SCODOG > 2.0.CO;2.

Young, G. S., S. M. Perugini, and C. W. Fairall, 1995: Convective wakes in the equatorial western Pacific during TOGA. Mon. Wea. Rev., 123, 110-123, doi:10.1175/1520-0493(1995)123<0110: CWITEW $>2.0 . \mathrm{CO} ; 2$.

Zhang, Y., and S. A. Klein, 2010: Mechanisms affecting the transition from shallow to deep convection over land: Inferences from observations of the diurnal cycle collected at the ARM Southern Great Plains site. J. Atmos. Sci., 67, 2943-2959, doi:10.1175/2010JAS3366.1.

Zuidema, P., and Coauthors, 2012: On trade wind cumulus cold pools. J. Atmos. Sci., 69, 258-280, doi:10.1175/ JAS-D-11-0143.1. 